\title{
Familial dilated cardiomyopathy and isolated left ventricular noncompaction associated with lamin A/C gene mutations
}

\author{
Manuel Hermida-Prieto, Lorenzo Monserrat, Alfonso Castro-Beiras, Rafael Laredo, \\ Rafaela Soler, Jesus Peteiro, Esther Rodríguez, Beatriz Bouzas, Nemesio Álvarez, \\ Javier Muñiz, Marisa Crespo-Leiro
}

\begin{abstract}
LMNA mutations have been associated with familial or sporadic dilated cardiomyopathy (DC), with or without conduction system disease. We studied the LMNA gene in 67 consecutive patients with DC (18 had familial DC, 17 had possible familial DC, and 32 sporadic DC). From genomic DNA, coding regions of the LMNA gene were amplified by polymerase chain reaction, studied by single-strand conformation polymorphism, and cycle sequenced. Mutations were confirmed by restriction fragment length polymorphism. Two disease-causing mutations were found in families A and B. In family A, a novel R349L mutation was present in the mother and her identical twin daughters. They required cardiac transplantation at 36, 18, and 20 years of age. In family B, the R190W mutation was present in 2 cousins with DC and without conduction system disease (1 had cardiac transplantation at 45 years of age and 1 died suddenly at 46 years of age) and in 2 of their sons. The mothers of the 2 affected patients died due to cardiac causes in their 40s (1 died suddenly). One of the carriers fulfilled diagnostic criteria for isolated left ventricular noncompaction. Our data associated the R349L and R190W mutations in LMNA with severe forms of familial DC. LMNA mutations should be considered in the genetic screening of patients with familial DC without conduction system disease. Isolated left ventricular noncompaction may be part of the phenotypic spectrum of the laminopathies.
\end{abstract}

Approximately $33 \%$ to $50 \%$ of cases of idiopathic dilated cardiomyopathy (DC) are familial.1, 2 and 3 Mutations within the LMNA A/C gene encoding lamin A/C have been identified as causing familial DC with conduction system disease or variable myopathy,4, 5, 6, 7, 8, 9 and 10 autosomal dominant EmeryDreifuss muscular dystrophy, limb girdle muscular dystrophy, familial partial lipodystrophy, CharcotMarie-Tooth type 2 axonal neuropathy, mandibuloacral dysplasia, and Hutchinson-Gilford progeria syndrome.11, 12, 13, 14, 15, 16 and 17 The objective of this study was the identification of mutations in the lamin A/C gene in cases of familial or sporadic DC with or without conduction system disease.

\section{Methods}

The first 67 patients with DC from different families consecutively referred to our familial cardiomyopathies clinic were included. Fifty were patients with previous cardiac transplantation for idiopathic DC and 17 were patients with idiopathic DC controlled in our heart failure clinics. These patients and their relatives were evaluated by detailed analysis of their medical histories, physical examination, 12-lead electrocardiography, blood analysis, and M-mode, 2-dimensional, and Doppler echocardiography and genetic analysis, as described in the following. Familial DC was defined as $\geq 2$ patients with idiopathic DC within the same family. Possible familial DC was considered when $\geq 1$ relative had echocardiographic left ventricular enlargement (left ventricular end-diastolic diameter $>112 \%$ of the predicted diameter according to Henry's formula).18 Informed consent was obtained from all subjects in accordance with the guidelines of the local ethics committee.

Genomic DNA was isolated from peripheral blood samples using QIAmp columns (Qiagen, Chatsworth, California) according to the manufacturer's instructions. Primers for all lamin A/C gene exons were designed from public sequences (GenBank accession numbers L12399 [exon 1], L12400 [exon 2], and L12401 [exons 3 to 12 and mRNA]). For exons 6 and 3, primers described by Brodsky et al5 and Fatkin et al6 were employed. DNA samples were amplified by polymerase chain reaction, and single-strand conformation polymorphism analysis was done with the SSCP Startet kit (Amersham Pharmacia Biotech, Uppsala, Sweden). Anomalous single-strand conformation polymorphism conformers were reamplified and purified, and DNA sequences were determined through automated DNA sequencing 
with the ABI Prism dye-terminator cycle sequencing kit (Applied Biosystems, Foster City, California). The sequence variants in exons 3 and 6 were confirmed with modified restriction enzyme digestion. The mutation in codon 190 in exon 3 creates a restriction site for FauI. For the mutation in codon 349, a partial Tha I site was completed by introducing 1 mismatched nucleotide (underlined) with polymerase chain reaction and primers F 5'-AGCGGGAGATGGCCGAGA G-3' and R 5'TCTAGTCAAGGCCAGTTGCC-3'. The resultant 200-bp fragment was digested with ThaI. The presence of a $\mathrm{G} \rightarrow \mathrm{T}$ transversion at nucleotide residue 1046 in exon 6 is not cut, whereas the wild type allows cleavage for a 179-bp fragment plus a 21-bp fragment.

\section{Results}

Of the 67 index patients, 18 had familial DC, 17 had possible familial DC, and 32 were considered to have sporadic DC. All patients were white. Clinical data of the families have been presented elsewhere.4

Two likely disease-causing mutations were found in 2 different families. Figure 1 shows their respective pedigrees. Clinical and electrocardiographic data are presented in TABLE 1 and TABLE 2.

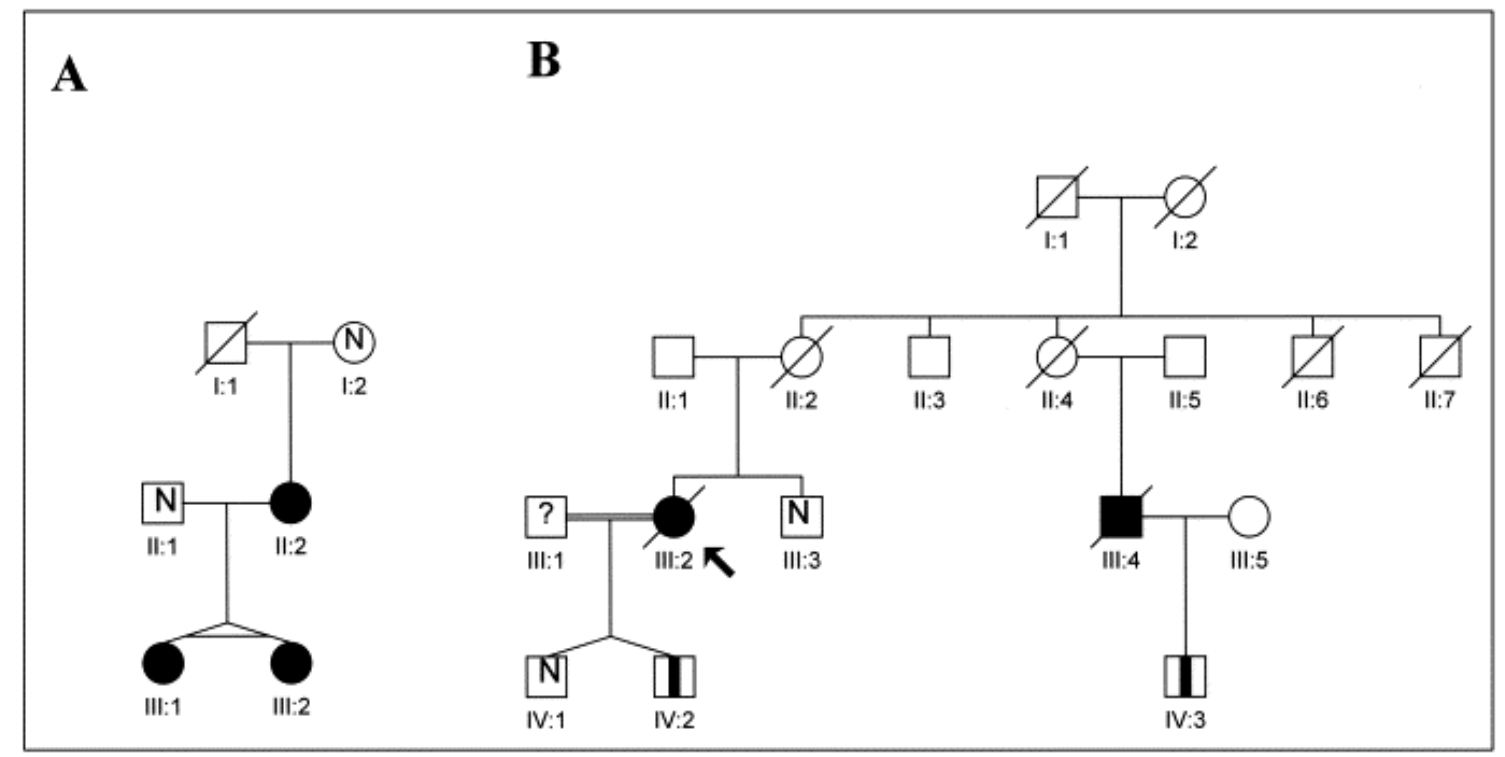

Figure 1. Pedigrees of families A $(A)$ and B $(B)$ show affected females (solid circles) and males (solid squares), unaffected subjects $(N)$, nonstudied family members (open symbols), mutant carriers (vertical bars), and a proband (arrow). 
Table 1. Families With Lamin A/C Mutations: Clinical Characteristics of Probands and Their Affected Relatives

\begin{tabular}{|c|c|c|c|c|c|c|c|}
\hline Family & Patient & Mutation & Age (yrs) at Onset & Age (yrs) at Event & LVEDD (mm) & $\operatorname{LEVF}(\%)$ & CPK \\
\hline A & $\mathrm{II}: 2$ & R349L & 31 & Transplant (36) & 62 & 21 & 29 \\
\hline A & III:1 & R349L & 17 & Transplant (18) & 61 & 22 & 96 \\
\hline A & III:2 & R349L & 17 & Transplant (20) & 55 & 40 & 33 \\
\hline B & III:4 & R190W & 40 & Transplant (46) & 58 & 32 & 11 \\
\hline B & III:2 & R190W & 45 & Sudden death (47) & 59 & 49 & 49 \\
\hline B & IV:3 & R190W & 19 & - & 46 & 58 & - \\
\hline B & IV:2 & R190W & 22 & - & 55 & 62 & $220 / 366 *$ \\
\hline B & IV:1 & No & 22 & - & - & - & 92 \\
\hline B & II:4 & $?$ & - & Sudden death (40) & - & - & - \\
\hline B & $\mathrm{II}: 2$ & $?$ & - & Death (44), probable DC & - & - & - \\
\hline
\end{tabular}

$\mathrm{CPK}=$ creatine phosphokinase LVEDD = left ventricular end-diastolic diameter; $\mathrm{LVEF}=$ left ventricular ejection fraction.

* Values at first and final follow-up.

Table 2. Families With Lamin A/C Mutations: Electrocardiographic Characteristics at First Evaluation and at Final Follow-up

\begin{tabular}{lcccccc}
\hline Family & Patient & Mutation & Months Between ECGs & Initial PR (ms) & Final PR (ms) & Comments \\
\hline A & & & & & - & Atrial fibrillation \\
A & II:2 & R349L & 36 & 150 & 150 & 130 \\
A & III:1 & R349L & 8 & 140 & 195 \\
B & III:2 & R349L & R190W & 56 & 157 & 202 \\
B & III:2 & R190W & 30 & 155 & 150 & 175 \\
B & IV:3 & R190W & 16 & 166 & LVNC \\
B & IV:2 & R190W & 15 & & 160 \\
\hline
\end{tabular}

ECGs = electrocardiograms; LVNC = left ventricular noncompaction; PR = PR interval.

In family A, an abnormal single-strand conformation polymorphic motility was found in exon 6 of 3 affected family members, a woman (index case) and her identical twin daughters (FIGURE 1 and FIGURE 2). In all 3 cases, a heterozygous guanine-to-thymidine transversion was found at nucleotide 1046 of the lamin A/C gene. This sequence variation is predicted to substitute arginine for leucine at residue 349 (R349L). The mother of the index patient and 20 clinically unaffected relatives of the index patient's deceased father were studied. None had the mutation. The mutation was not found in 200 chromosomes of 100 healthy controls. This mutation affects a highly conservative region that is identical in Xenopus laevensis, Gallus gallus, and Rattus norvegicus. To our knowledge, this mutation has not been previously described. 


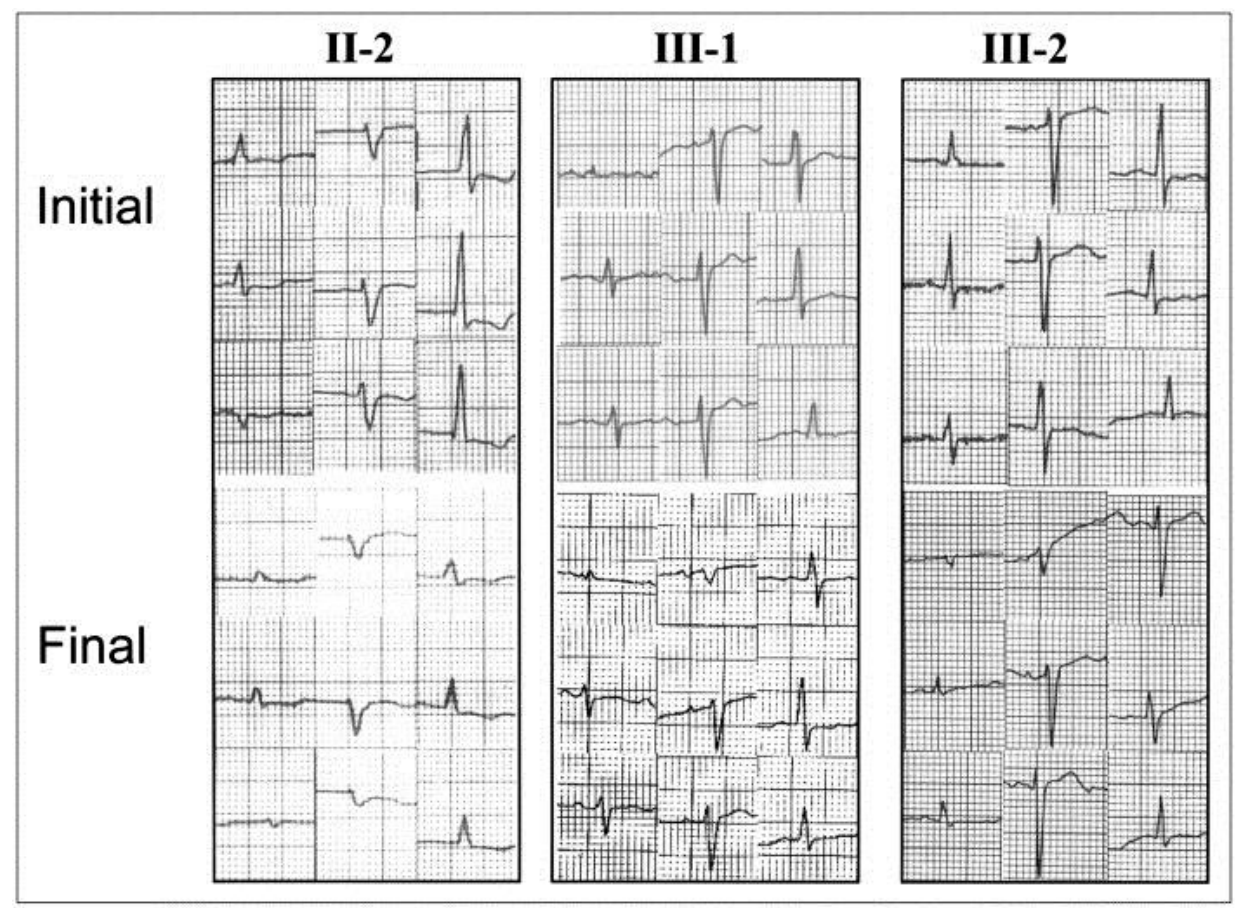

Figure 2. Electrocardiograms of affected patients in family A at their initial (upper row) and final follow-up (lower row). From up to down and from left to right, leads I, II, III, and $\mathrm{V}_{1}$ to $\mathrm{V}_{6}$ are presented. Low voltage is present in the limb leads of the 3 patients, and a decrease in voltage is seen from the initial to the final electrocardiogram in all of them.

In family $\mathrm{B}$, a heterozygous cytosine-to-thymidine transversion was found at nucleotide 568 in exon 3 of the lamin A/C gene in 2 cousins with DC (Figure 1). This sequence variation is predicted to substitute arginine for tryptophane at residue 190 (R190W). This mutation has been recently associated with familial DC.4 and 19 The mutation was found in 2 sons of these 2 patients. The 19-year-old son of the patient who had received a transplant (IV:3, Figure 1) was asymptomatic, with an abnormal electrocardiogram with high voltages, incomplete right bundle branch block, and abnormal repolarization (IV:3, Figure 3). The echocardiogram and cardiac magnetic resonance imaging showed prominent trabeculations with deep recesses in a thickened left ventricular wall affecting distal portions of the posterior and lateral walls, with a thin compact epicardial layer (Figure 4). These findings are diagnostic of isolated left ventricular noncompaction.20 and 21 Left ventricular end-diastolic diameter and ejection fraction were within normal limits. 


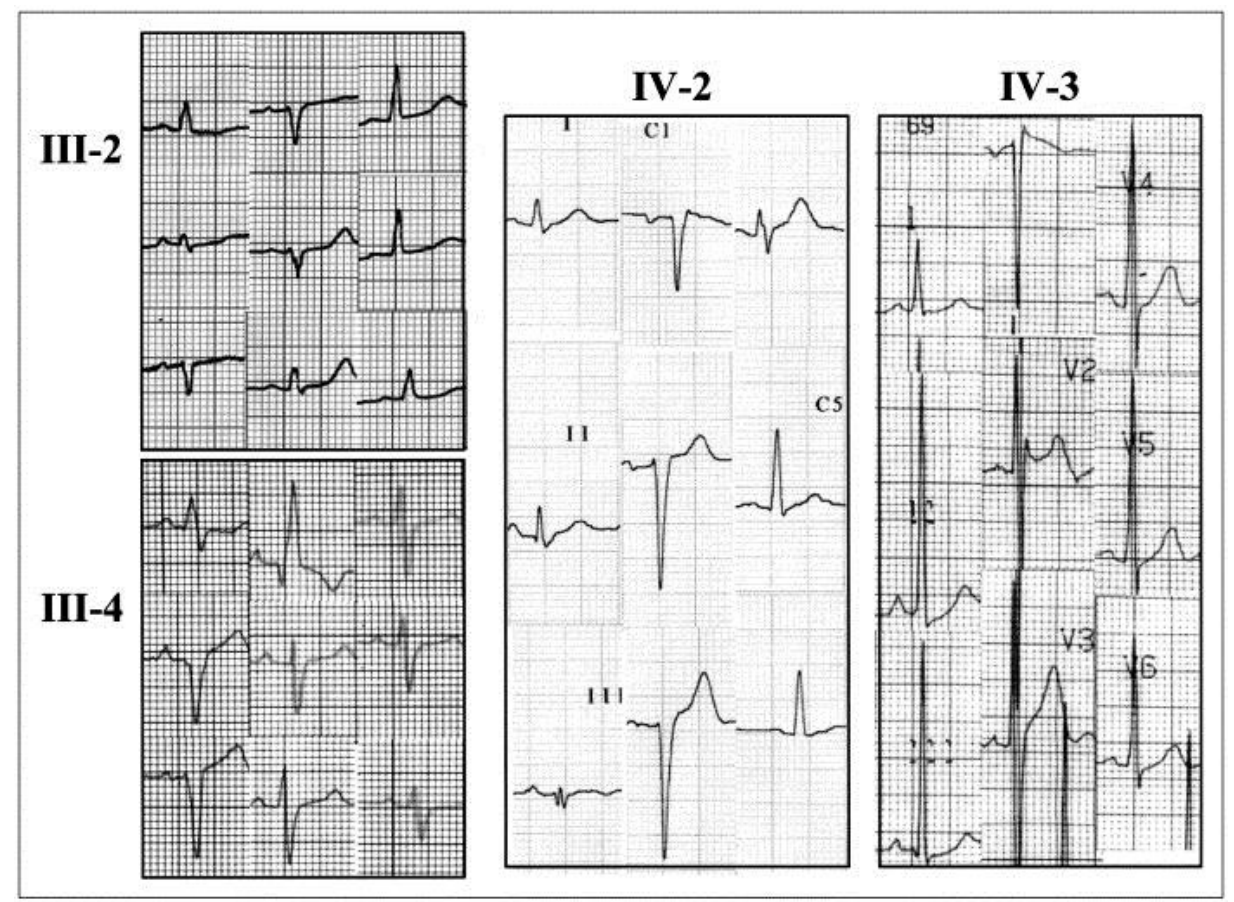

Figure 3. Electrocardiograms of affected patients in family B. From up to down and from left to right, leads I, II, III, and $\mathrm{V}_{1}$ to $\mathrm{V}_{6}$ are presented. All patients had normal PR intervals. Subjects III:2 and IV:2 had low voltage in the limb leads, subject III:4 showed incomplete right bundle branch block, and subject IV:3 was the patient with left ventricular noncompaction.
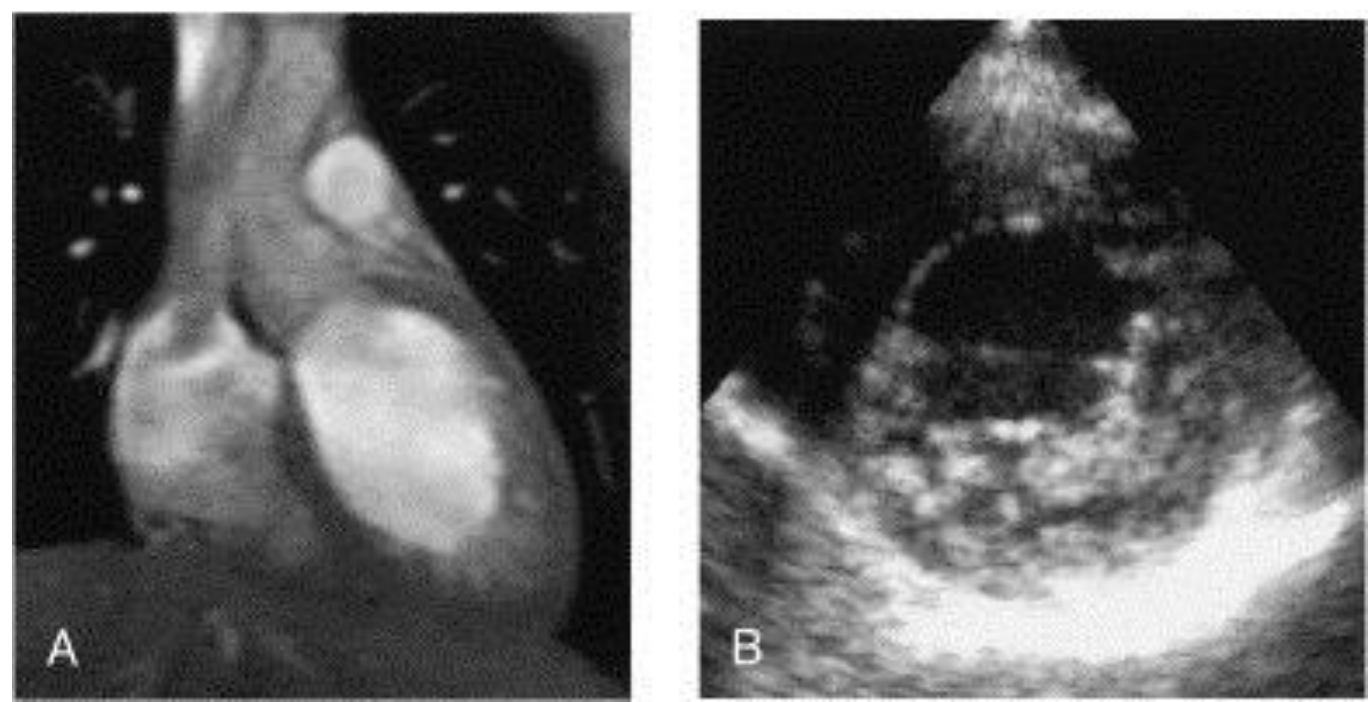

Figure 4. Magnetic resonance and echocardiographic images of patient IV:3 from family B. (A) Magnetic resonance coronal longaxis view of the heart shows apical left ventricular wall thickening with prominent trabeculations and recesses filled with contrast. (B) Echocardiographic parasternal short-axis view at the midventricular level also shows left ventricular wall thickening with prominent trabeculations and deep recesses affecting $>2 / 3$ of the total wall thickness in the posterolateral wall. 
One of the 23-year-old twin sons of the affected patient (IV:2, Figure 1), who also carried the mutation, had left ventricular enlargement, an abnormal electrocardiogram with amputation of the $\mathrm{R}$ wave in leads $\mathrm{V}_{1}$ to $\mathrm{V}_{3}$ and low voltage in the limb leads (IV:2, Figure 3), and a moderate increase in serum creatine phosphokinase. Cardiac magnetic resonance imaging showed mild left ventricular dilation without other abnormalities. The twin brother was completely normal and did not carry the mutation.

\section{Discussion}

The most relevant findings of this study were (1) the description of 1 novel and 1 recurrent mutation in the lamin A/C gene associated with severe forms of familial DC and (2) the identification of isolated left ventricular noncompaction in a young carrier of the R190W lamin A/C mutation.

The novel R349L mutation affects a highly conserved residue localized in exon 6, which is in the central rod domain of the lamin A/C gene. Mutations in other residues in this region have been associated with Emery-Dreifuss muscular dystrophy, DC, and limb girdle muscular dystrophy.4, 10, 11 and 13 This mutation segregates with disease in the family and is conserved through evolution, so we consider that it likely (but not definitely) causes disease. Our patients had a severe form of DC with early clinical onset and fast progression and without signs of skeletal myopathy or creatine phosphokinase elevations. Conduction system defects were not apparent except in 1 patient.

The R190W mutation has been associated with severe forms of familial DC with conduction system disease, 4 and 19 but atrioventricular conduction defects were absent in the family with this mutation. Our results support the convenience of using lamin $\mathrm{A} / \mathrm{C}$ as a candidate gene in familial $\mathrm{DC}$ without conduction abnormalities.

In these 2 families there were 3 premature sudden deaths in patients without severe clinical deterioration. Becane et al22 also found that sudden death was frequent in patients with DC secondary to lamin $\mathrm{A} / \mathrm{C}$ mutations, even in those with pacemakers. Prophylactic therapy with an implantable cardioverter defibrillator may be indicated in these patients.

Lamin A/C mutations produce different human diseases, but to our knowledge there has been no previous report of lamin $\mathrm{A} / \mathrm{C}$ mutations associated with isolated left ventricular noncompaction. Our findings have yielded some novel insights into this disease. Left ventricular noncompaction is a genetically heterogeneous disease characterized by prominent ventricular myocardial trabeculations and deep intertrabecular recesses believed to be due to an abnormal arrest in endomyocardial embryogenesis.23, 24 and 25 Progressive left ventricular systolic dysfunction and dilation are typical features of the disease.23 and 24 Mutations in G4.5 (encoding taffazin, a protein with unknown function) and in the $\alpha$-dystrobrevin gene (a cytoskeletal protein in the dystrophin-associated glycoprotein complex) have been associated with this disease.24, 25, 26, 27 and 28 Mutations in G4.5 produce a wide phenotypic spectrum of cardiomyopathies, from Barth's syndrome to left ventricular noncompaction associated or not with other congenital heart defects or isolated DC, even within a single family.25 A recent report has suggested that mutations in the Cypher/ZASP gene, which encodes a protein that is component of the $\mathrm{Z}$ line of the sarcomere, can also cause DC and left ventricular noncompaction.29 It would not be surprising that mutations in lamin $\mathrm{A} / \mathrm{C}$ could also produce a comparable phenotypic heterogeneity. Interestingly, another protein factor that may be implicated in the process of compaction of the ventricular myocardium is emerin.28 Emerin mutations cause phenotypes similar to those produced by different lamin $\mathrm{A} / \mathrm{C}$ mutations, 11 and 12 and there is a tight interaction between emerin and lamins $\mathrm{A} / \mathrm{C}$ in the nuclear membrane.12 All these data support the hypothesis of a causal relation between the R190W mutation and isolated left ventricular noncompaction in our patients. However, this phenotype was not found in any other of the studied patients in this or in the 2 previously described families, 4 and 19 so we have to be cautious in the interpretation of this finding, which may have been incidental.

\section{References}

1. V.V. Michels, P.P. Moll, F.A. Miller, A.J. Tajik, J.S. Chu, D.J. Driscoll, J.C. Burnett, R.J. Rodeheffer, J.H. Chesebro, H.D. Tazelaar. The frequency of familial dilated cardiomyopathy in a series of patients with idiopathic dilated cardiomyopathy. N Engl J Med, 326 (1992), pp. 77-82.

2. E. Grunig, J.A. Tasman, H. Kucherer, W. Franz, W. Kubler, H.A. Katus. Frequency and phenotypes of familial dilated cardiomyopathy. J Am Coll Cardiol, 31 (1998), pp. 186-194.

3. L. Monserrat, M. Hermida, B. Bouzas, I. Mosquera, N. Mahon, J. Peteiro, N. Alvarez, M. Penas-Lado, M. Crespo, A. Castro-Beiras. Familial dilated cardiomyopathy in cardiac transplanted patients. Rev Esp Cardiol, 55 (2002), pp. 725-732. 
4. E. Arbustini, A. Pilotto, A. Repetto, M. Grasso, A. Negri, M. Diegoli, C. Campana, L. Scelsi, E. Baldini, A. Gavazzi, L. Tavazzi. Autosomal dominant dilated cardiomyopathy with atrioventricular block: a lamin A/C defect related disease. J Am Coll Cardiol, 39 (2002), pp. 981-990.

5. G.L. Brodsky, F. Muntoni, S. Miocic, G. Sinagra, C. Sewry, L. Mestroni. Lamin A/C gene mutation associated with dilated cardiomyopathy with variable skeletal muscle involvement. Circulation, 101 (2000), pp. 473-476.

6. D. Fatkin, C. MacRae, T. Sasaki, M.R. Wolff, M. Porcu, M. Frenneaux, J. Atherton, H.J. Vidaillet, S. Spudich, U. De Girolami, et al. Missense mutations in the rod domain of the lamin A/C gene as causes of dilated cardiomyopathy and conduction-system disease. N Engl J Med, 341 (1999), pp. 1715-1724.

7. J. Genschel, B. Bochow, S. Kuepferling, R. Ewert, R. Hetzer, H. Lochs, H. Schmidt. An R644C mutation within lamina A extends the mutations causing dilated cardiomyopathy. Hum Mutat, 17 (2001), p. 154.

8. J. Genschel, P. Baier, S. Kuepferling, M.J. Proepsting, C. Buettner, R. Ewert, R. Hetzer, H. Lochs, H. Schmidt. A new frameshift mutation at codon 466 (1397delA) within the LMNA gene. Hum Mutat, 16 (2000), p. 278.

9. P.M. Jakobs, E.L. Hanson, K.A. Crispell, T.W. Keegan, K. Schilling, T.B. Icenogle, M. Litt, R.E. Hershberger. Novel lamin A/C mutation in two families with dilated cardiomyopathy and conduction system disease. J Card Fail, 7 (2001), pp. 249-256.

10. M.R. Taylor, P.R. Fain, G. Sinagra, M.L. Robinson, A.D. Robertson, E. Carniel, A. Di Lenarda, J. Bohlmeyer, D. Ferguson, G.L. Brodsky, et al. Natural history of dilated cardiomyopathy due to lamin A/C gene mutations. J Am Coll Cardiol, 5 (2003), pp. 771-780.

11. G. Bonne, E. Mercuri, A. Muchir, A. Urtizberea, H.M. Becane, D. Recan, L. Merlini, M. Wehnert, R. Boor, U. Reuner, et al. Clinical and molecular genetic spectrum of autosomal dominant Emery-Dreifuss muscular dystrophy due to mutation of the lamina A/C gene. Ann Neurol, 48 (2000), pp. 170-180.

12. W.H. Raharjo, P. Enarson, T. Sullivan, C.L. Stewart, B. Burke. Nuclear envelope defects associated with LMNA mutations cause dilated cardiomyopathy and Emery-Dreifuss muscular dystrophy. J Cell Sci, 114 (2001), pp. 4447-4457.

13. A. Muchir, G. Bonne, A.J. van der Kooi, M. van Meegen, F. Baas, P.A. Bolhuis, M. de Visser, K. Scwartz. Identification of mutations in the gene encoding lamins $\mathrm{A} / \mathrm{C}$ in autosomal dominant muscular dystrophy with atrioventricular conduction disturbances (LGMD1B). Hum Mol Genet, 9 (2000), pp. 1453-1459.

14. S. Shackleton, D.J. Lloyd, S.N. Jackson, R. Evans, M.F. Niermeijer, B.M. Singh, H. Schmidt, G. Brabant, S. Kumar, P.N. Durrington, et al. LMNA, encoding lamin A/C, is mutated in partial lipodystrophy. Nat Genet, 24 (2000), pp. 153-156.

15. A. De Sandre Giovannoli, M. Chaouch, S. Kozlov, J.M. Vallat, M. Tazir, N. Kassouri, P. Szepetowski, T. Hammadouche, A. Vandenberghe, C.L. Stewart. Homozygous defects in LMNA, encoding lamin A/C nuclearenvelope proteins, cause autosomal recessive axonal neuropathy in human (Charcot-Marie-Tooth disorder type 2) and mouse. Am J Med Genet, 70 (2002), pp. 726-736.

16. G. Novelli, A. Muchir, F. Sanguiuolo, A. Helbling-Leclerc, M.R. D'Apice, C. Massart, F. Capon, P. Sbraccia, M. Federici, R. Lauro, et al. Mandibuloacral dysplasia is caused by a mutation in LMNA-encoding lamin A/C. Am J Med Genet, 71 (2002), pp. 426-431.

17. Eriksson M, Brown WT, Gordon LB, Glynn MW, Singer J, Scott L, Erdos MR, Robbins CM, Moses TY, Berglund $\mathrm{P}$, et al. Recurrent de novo point mutations in lamin A cause Hutchinson-Gilford progeria syndrome. Nature 2003;16.

18. M.K. Baig, J.H. Golman, A.L. Caforio, A.S. Coonar, P.J. Keeling, W.J. McKenna. Familial DCM: cardiac abnormalities are common in asymptomatic relatives and may represent early disease. J Am Coll Cardiol, 31 (1998), pp. 195-201.

19. R. Anan, H. Niimura, T. Sasaki, J.G. Seidman, C.E. Seidman, S. Minagoe, C. Tei. A novel lamin A/C missense mutation in a family with autosomal dominant dilated cardiomyopathy with conduction abnormalities. J Am Coll Cardiol, 39 (suppl A) (2002), p. 136.

20. Y. Agmon, H.M. Connolly, L.J. Olson, B.K. Khanderia, J.B. Seward. Noncompaction of the ventricular myocardium. J Am Soc Echocardiogr, 12 (1999), pp. 859-863.

21. R. Jenni, E. Oechslin, J. Schneider, C.A. Jost, P.A. Kaufmann. Echocardiographic and pathoanatomical characteristics of isolated left ventricular non-compaction: a step towards classification as a distinct cardiomyopathy. Heart, 86 (2001), pp. 599-600.

22. H.M. Becane, G. Bonne, S. Varnous, A. Muchir, V. Ortega, E.H. Hammouda, J.A. Urtizberea, T. Lavergne, M. Fardeau, B. Eymard, et al. High incidence of sudden death with conduction system and myocardial disease due to lamins A and C gene mutation. Pacing Clin Electrophysiol, 23 (2000), pp. 1661-1666.

23. T.K. Chin, J.K. Perloff, R.G. Williams, K. Jue, R. Mohrmann. Isolated noncompaction of left ventricular myocardium: a study of eight cases. Circulation, 82 (1990), pp. 507-513

24. F. Ichida, Y. Hamamichi, T. Miyawaki, Y. Ono, T. Kamiya, T. Akagi, H. Hamada, O. Hirose, T. Isobe, K. Yamada, et al. Clinical features of isolated noncompaction of the ventricular myocardium: long-term clinical course, hemodynamic properties, and genetic background. J Am Coll Cardiol, 34 (1999), pp. 233-240.

25. F. Ichida, S. Tsubata, K.R. Bowles, N. Haneda, K. Uese, T. Miyawaki, J. Dreyer, J. Messina, H. Li, N.E. Bowles, J.A. Towbin. Novel gene mutations in patients with left ventricular noncompaction or Barth Syndrome. Circulation, 103 (2001), pp. 1256-1263.

26. S.B. Bleyl, B.R. Mumford, V. Thompson, J.C. Carey, T.J. Pysher, T.K. Chin, K. Ward. Neonatal, lethal noncompaction of the left ventricular myocardium is allelic with Barth syndrome. Am J Hum Genet, 61 (1997), pp. 868-872. 
27. R. Chen, T. Tsuji, F. Ichida, K.R. Bowles, X. Yu, S. Watanabe, K. Hirono, S. Tsubata, Y. Hamamichi, J. Ohta, et al. Mutation analysis of the G4.5 gene in patients with isolated left ventricular noncompaction. Mol Genet Metab, 77 (2002), pp. 319-325.

28. E. Zambrano, S.J. Marshalko, C.C. Jaffe, P. Hui. Isolated noncompaction of the ventricular myocardium: clinical and molecular aspects of a rare cardiomyopathy. Lab Invest, 82 (2002), pp. 117-122.

29. M. Vatta, B. Mohapatra, S. Jimenez, X. Sanchez, G. Faulkner, Z. Perles, G. Sinagra, J. Lin, T.M. Vu, W. Zhou, et al. Mutations in Cypher/ZASP in patients with dilated cardiomyopathy and left ventricular non-compaction. J Am Coll Cardiol, 42 (2003), pp. 2014-2027. 